doi:10.12662/2359-618xregea.v9i1.p48-63.2020

ARTIGOS

\title{
ENGAJAMENTO NO TRABALHO: ANÁLISE BIBLIOMÉTRICA DA PRODUÇÃO CIENTÍFICA INTERNACIONAL
}

\author{
ENGAGEMENT AT WORK: BIBLIOMETRIC \\ ANALYSIS OF INTERNATIONAL SCIENTIFIC \\ PRODUCTION
}

\begin{abstract}
Bruna Eduarda Fiorentin brunaefiorentin@gmail.com Graduanda em Administração pela Universidade Estadual do Centro-Oeste. Santa Cruz - PR $-B R$.
\end{abstract}

Silvio Roberto Stefano professor-silvio@hotmail.com Pós-Doutor em Administração pela Univali (2013-2014).

Professor Associado da Universidade Estadual do Centro-Oeste UNICENTRO. Docente do Mestrado Profissional em Administração da UNICENTRO - PPGADM. Santa Cruz - PR - BR.

Juliana de Souza Santos julianadesouzasantos08@gmail.com Graduanda em Administração pela Universidade Estadual do Centro-Oeste. Santa Cruz - PR $-B R$.

\section{RESUMO}

Em face das inúmeras mudanças na gestão de pessoas nas empresas, o engajamento do trabalho ganha importância como fator de motivação intrínseca, caracterizada por um alto nível de energia e uma forte identificação com o próprio trabalho. Esta pesquisa teve como objetivo principal desenvolver uma análise bibliométrica da produção de artigos internacionais sobre o tema, disponíveis nas bases Periódicos Capes e Scopus, no período de 2008-2018. Foram identificados, preliminarmente, 112 artigos, dos quais 20 foram efetivamente analisados, considerando artigos acima de 150 citações em outras pesquisas. Conclui-se que, nas publicações internacionais, há uma predominância de estudos de autores holandeses, artigos de abordagem quantitativa, em revistas sobre administração, gestão e psicologia, visando definir as correlações de engajamento no trabalho com outros construtos da área de gestão de pessoas.

Palavras-chave: Engajamento. Gestão de Pessoas. Comportamento Organizacional. Análise Bibliométrica.

\section{ABSTRACT}

In the face of the countless changes on human's management in companies, the work engagement has earned some importance as a factor of intrinsic motivation characterized as a high level of energy and strong identification with its own work. This research had as main objective to develop a bibliometric analysis of the international papers produced regarding this theme, available on Periódicos Capes and Scopus databases, in the period of 2008 to 2018. A total of 112 articles were previously identified, 20 of those were effectively analyzed, considering the ones with more than 150 citations in other papers. In conclusion, in the international publications, there is a predominance of Dutch authors' studies, articles of quantitative
\end{abstract}


approach, journals of management and psychology, aiming to define the correlations between work engagement and others constructs of Human Resource Management area.

Keywords: Engagement. Human Resource Management. Organizational Behavior. Bibliometric Analysis.

\section{INTRODUÇÃO}

Na última década, o contexto das organizações tem mudado, principalmente em relação a seus colaboradores, com novas exigências, não somente focando na questão salarial e nas necessidades básicas, mas também nas demandas de saúde, trabalhistas e de desenvolvimento. Segundo Aveiro et al. (2017, p. 1), essas mudanças "têm afetado o ambiente organizacional, em que os funcionários buscam também o autodesenvolvimento, o envolvimento em atividades prazerosas e a realização pessoal".

Nesse sentido, ganha importância o conceito de engajamento no trabalho, que se relaciona com o fato de o indivíduo sentir prazer em atividades laborais por meio do equilíbrio do seu trabalho em termos de saúde física e psicológica (PORTO-MARTINS; BOSSO-MACHADO; BENEVIDES-PEREIRA, 2013), de modo que estudar o engajamento no ambiente de trabalho é uma questão de bastante relevância para a gestão de pessoas contemporânea.

Pauli et al. (2017, p. 76) entendem que o engajamento é um fenômeno que ocorre no ambiente organizacional, "geralmente associado ao bem-estar físico e mental dos trabalhadores, influenciando tanto no vigor e energia, quanto na absorção e concentração no trabalho"; ou seja, estar engajado é um fator motivacional positivo relacionado ao bem-estar ou a uma satisfação caracterizada por um alto nível de energia e uma forte identificação com o próprio trabalho.

Nesse sentido, Oliveira e Rocha (2017) destacam que os antecedentes individuais e situacionais do engajamento no trabalho são influenciados por diferenças individuais, medidas pelo construto de avaliações autorreferentes, pela avaliação das práticas de recursos humanos e pela qualidade da relação líder-liderado, isto é, as complexas relações entre funcionários e gestão das empresas, podendo trazer impactos positivos ou negativos na produtividade, rotatividade e satisfação no trabalho.

São relevantes os apontamentos de Truss et al. (2013, p. 13), quando afirmam que "não temos uma "grande ciência" de engajamento ou entre o engajamento dos funcionários, por um lado, e a gestão de recursos humanos, por outro", ou seja, é um constructo que precisa ser mais pesquisado e analisado no contexto organizacional.

Assim, entende-se que esse é um tema atual e de interesse da área de administração e sociedade em geral, já que as pesquisas apontam que desenvolver engajamento no trabalho, além de gerar maior bem-estar, também pode melhorar os índices organizacionais.

A partir disso, foram formuladas as seguintes questões de pesquisa: qual é o número de publicações que se referem ao engajamento no trabalho nos últimos anos? De onde são os autores e quais as revistas que mais se destacam ou publicam sobre o tema? Quais são as contribuições dessas publicações para o entendimento do tema? Quais são os subtemas de interesse e suas relações com o tema principal? Qual é o perfil metodológico adotado? Portanto, este trabalho teve como objetivo principal desenvolver uma análise bibliométrica da produção de artigos internacionais sobre o construto Engajamento no Trabalho, de modo a compreender melhor esse conceito e o que tem sido estudado sobre ele, nos últimos 10 anos.

Esta pesquisa teve como abordagem metodológica a análise bibliométrica dos artigos encontrados com as palavras-chave "Engagement", "Work Engagement" e "Utrecht Work Engagement Scale" nas bases de pesquisa Periódicos Capes e Scopus com foco nas áreas de gestão de pessoas, administração e comportamento organizacional. Foram encontrados 120 artigos com esse recorte, e foram, efetivamente, analisados os 20 artigos que possuíam mais de 150 citações em outros trabalhos.

Assim, este artigo se apresenta da se- 
guinte forma: na primeira parte, faz-se uma breve revisão teórica sobre engajamento no trabalho; na seção seguinte, são relatados os aspectos metodológicos utilizados para o alcance do objetivo; posteriormente, são apresentados, analisados e discutidos os resultados obtidos; por fim, são apresentadas as considerações finais e as referências utilizadas no estudo.

\section{REFERENCIAL TEÓRICO}

Neste tópico, serão abordados os principais conceitos de Engajamento no Trabalho, com o objetivo de explicitar como ele é entendido pelos autores da área, assim como os principais aspectos do comportamento humano ligados a ele. Também se identificam quais são seus principais antecedentes, como causas, tanto pessoais, quanto do próprio ambiente de trabalho. Por fim, são elencados alguns dos efeitos positivos e negativos decorrentes do engajamento no trabalho.

$\mathrm{O}$ conceito de engajamento tem ganhado destaque nos últimos anos com o surgimento da Psicologia Positiva, que busca desenvolver maior bem-estar e saúde nos diversos âmbitos da vida de um indivíduo. Uma dessas áreas a serem levadas em consideração é o ambiente de trabalho, em que os indivíduos passam a maior parte de seu dia (HO; WONG; LEE, 2011).

Há uma preocupação com o engajamento no trabalho não só por uma perspectiva de compreender seu conceito, mas também quais são suas variáveis e como promovê-lo. Além disso, é indiscutível o fato de que o seu desenvolvimento é importante não só para gerar maior bem-estar aos trabalhadores, como também para melhorar o ambiente de trabalho e a produtividade, visto que pessoas mais engajadas produzem mais e com maior qualidade (LEROY et al., 2013).

Para entender engajamento, Schaufeli et al. (2002) explicam que engajamento no trabalho pode ser definido como um estado mental de positividade e imersão na atividade do trabalho, que é caracterizado pelo vigor, dedicação e absorção. Entendendo vigor como permanecer enérgica e mentalmente resiliente e disposto a investir esforços, persistindo ante as dificuldades. A dedicação implica manter-se com entusiasmo, inspirado para o trabalho e ter a experiência de significância, orgulho e desafio. E absorção pode ser descrita como uma concentração absoluta no trabalho e uma experiência de estar completamente absorto nele (SONNENTAG et al., 2012).

É importante destacar que o engajamento representa uma experiência simultânea e holística (KAHN, 1992; RICHET et al., 2010 apud CHRISTIAN; SLAUGHTER, 2011, p. 89) de energias cognitiva, física e emocional que os indivíduos levam para seu trabalho (RICH et al., 2010 apud CHRISTIAN; SLAUGHTER, 2011, p. 89). Portanto, indivíduos que são engajados têm uma experiência de conexão com seu trabalho em multiníveis.

Outro fator importante é que o engajamento é definido não como um estado e não como um traço; pode ser entendido a partir do conceito de "Flow" de Kahn (1990), um fluxo de concentração na tarefa que faz que o indivíduo diminua sua percepção da passagem de tempo no decorrer da realização do trabalho.

Sonnentag (2003) indica que o estado de engajamento pode flutuar durante o dia, dependendo da disposição diária, e ao longo do dia. Também em seu estudo, em 2012, o mesmo autor destaca que o descanso sentido de manhã prediz o engajamento no trabalho durante o dia, assim como a manutenção desse estado durante o dia prediz a disposição no final do dia de trabalho.

Assim, baseado em sua revisão sistemática da literatura, realizada em 2007, Christian e Slaughter (2011, p. 95) definem engajamento no trabalho como "um relativamente persistente estado de espírito, referindo-se ao investimento simultâneo de energias pessoais na experiência ou no desempenho do trabalho."

Entendendo o conceito de engajamento aplicado ao trabalho, o próximo passo poderia compreender como outros construtos podem estar relacionados a ele e de que forma. O engajamento pode ser causado tanto por questões da natureza das condições de trabalho, como 
por capacidades individuais. No primeiro caso, estudos mostram que alguns recursos, como suporte social com os colegas, feedback da performance, variedade de habilidades, autonomia e oportunidades para aprendizagem estão relacionados, positivamente, ao engajamento no trabalho (BAKKER, 2011).

Vários autores têm investigado as relações entre recursos pessoais e engajamento no trabalho. Por exemplo, tem sido mostrado que autoestima, autoeficácia e as habilidades de percepção e regulação das emoções são preditores positivos de engajamento no trabalho. Pessoas com autoavaliações positivas e altos níveis de resiliência predizem altos níveis de motivação intrínseca, de desempenho e satisfação com o trabalho e com a vida (BAKKER, 2011).

Outra questão discutida na literatura internacional disponível é a importância do papel do líder no engajamento de seus funcionários. Estudos como o de Tims, Bakker e Xanthopoulou (2011) falam sobre como os diferentes estilos de liderança podem influenciar, aumentando ou diminuindo o engajamento no trabalho dos subordinados.

Esses mesmos autores afirmam que os líderes que se comportam, transformando as normas e os valores dos empregados, motivando-os a ter um desempenho além de suas expectativas, que conseguem promover o envolvimento dos funcionários com os objetivos da organização e que têm uma visão inspirada são chamados de líderes transformacionais.

Eles têm quatro principais características que influenciam, de modo positivo, o engajamento no trabalho de seus subordinados, são elas: motivação que inspira, que é uma comunicação de um futuro atrativo; uma influência de idealização, que mostra a importância do trabalho em grupo e seus benefícios, demonstrando normas éticas bem desenvolvidas e oferecendo um modelo de regras aos subordinados; a consideração individual, que se refere a um líder que guia, dá suporte e estimula seus subordinados, que vê os indivíduos como seres únicos, que têm necessidades específicas e dá-lhes atenção para que seja congruente com a sua fase de desenvolvimento; e, por fim, o líder deve criar um ambiente de estimulação intelectual, em que desafia seus subordinados a pensarem os problemas em diferentes perspectivas (BREEVAART et al., 2013).

Além disso, esse líder que consegue manter um clima organizacional de motivação, inspiração e estimulação tem a possibilidade de desenvolver em seus subordinados os recursos pessoais que são preditores ao engajamento no trabalho, citados anteriormente (TIMS; BAKKER; XANTHOPOULOU, 2011).

Outra característica do ambiente organizacional que também é associada à promoção de engajamento no trabalho é a autonomia que o funcionário tem, para além disso, o "job crafting", definido como a capacidade de criar e recriar o seu trabalho diariamente, que também depende de uma característica pessoal de proatividade (PETROU et al., 2012).

Quando um indivíduo é proativo, ele tem a capacidade de identificar ou criar oportunidades que produzem condições favoráveis para a efetividade individual ou do time (BAKKER; TIMS; DERKS, 2012). Já o "job crafting” é a capacidade que um funcionário tem para criar mudanças efetivas, tanto físicas quanto cognitivas, no design do seu trabalho, escolhendo tarefas, negociando diferentes conteúdos de trabalho e atribuindo diferentes significados (PETROU et al., 2012).

Quanto à possibilidade de pontos negativos no desenvolvimento do engajamento no trabalho, alguns estudos têm-se preocupado quanto às relações entre esse construto com a ocorrência do "burnout" e sintomas depressivos. Quanto aos conceitos, "burnout" e engajamento no trabalho parecem ser totalmente contrários, entendendo o primeiro como um estado negativo de stress mental, de fadiga, percepções negativas quanto a colegas de trabalho e clientes, e, possivelmente, crises na competência profissional, acompanhada de grandes perdas de motivação (COLE et al., 2012). Como consequência, Hanaken e Schaufeli (2012) afirmam que o "burnout" e os sintomas depressivos são distintos, porém podem estar inter-relacionados, de modo que se assume que o "burnout" pode ser uma fase do de- 
senvolvimento de depressão. Porém, a escassez de estudos, nessa área, torna impossível afirmar empiricamente essas hipóteses.

Portanto, os estudos que relacionam engajamento no trabalho e burnout, como o de Cole et al., (2012), afirmam que, provavelmente, há uma importante ligação entre eles, seja uma convergência dos conceitos ou divergência, porém os estudos empíricos são poucos, e isso dificulta qualquer afirmação, sendo necessário, para os próximos estudos, desenvolver formas para testar e desenvolver essa área do tema.

A seguir, apresenta-se o quadro 1 com os principais conceitos desta pesquisa:

\section{METODOLOGIA}

Este estudo utilizou o método bibliométrico, que se caracteriza como uma técnica quantitativa de medição de produção e difusão do conhecimento científico (ARAÚJO, 2006). Silva, Hayashi e Hayashi (2011) relatam que a bibliometria abrange dois tipos de estudos: os descritivos e os avaliativos. As pesquisas descritivas referem-se à produtividade obtida pela contagem de livros, periódicos e outros formatos de comunicação; enquanto os estudos avaliativos estão relacionados ao uso da literatura por meio da contagem de referências e citações

Quadro 1 - Relação dos principais conceitos ligados ao Engajamento no Trabalho

\begin{tabular}{|l|l|}
\hline \multicolumn{1}{|c|}{ Construto } & \multicolumn{1}{c|}{ Definição } \\
\hline $\begin{array}{l}\text { Engajamento no } \\
\text { Trabalho }\end{array}$ & $\begin{array}{l}\text { "Estado mental de positividade e imersão na atividade do trabalho, que é caracterizado } \\
\text { pelo vigor, dedicação e absorção." (SCHAUFELI et al., 2002) }\end{array}$ \\
\hline Vigor & $\begin{array}{l}\text { "Permanecer energicamente e mentalmente resiliente e disposto a investir esforços, } \\
\text { persistindo frente às dificuldades." (SONNENTAG et al., 2012) }\end{array}$ \\
\hline Dedicação & $\begin{array}{l}\text { "Manter-se com entusiasmo e inspirado para o trabalho e ter a experiência de } \\
\text { significância, orgulho e desafio no trabalho." (SONNENTAG et al., 2012) }\end{array}$ \\
\hline Absorção & $\begin{array}{l}\text { "Concentração absoluta no trabalho e uma experiência de estar completamente absorto } \\
\text { no trabalho." (SONNENTAG et al., 2012) }\end{array}$ \\
\hline "Job Crafting” & $\begin{array}{l}\text { "Capacidade que um funcionário tem para criar mudanças efetivas, tanto físicas, } \\
\text { quanto cognitivas, no design do seu trabalho, escolhendo tarefas, negociando diferentes } \\
\text { conteúdos de trabalho, e atribuindo diferentes significados ao seu trabalho" (PETROU } \\
\text { et al., 2012). }\end{array}$ \\
\hline
\end{tabular}

Fonte: dados da pesquisa.

A partir do entendimento de engajamento, a área de gestão de pessoas nas empresas tem a possibilidade de compreender melhor sobre o bem-estar do trabalhador em relação ao trabalho, de modo a operar no ambiente organizacional para desenvolver recursos pessoais, de performance, assim como líderes e situações de modo que os seus subordinados estejam em alinhamento com as metas da organização e possam, além de se sentirem melhor e mais valorizados no ambiente de trabalho, colaborar para o desenvolvimento da empresa, aumentando a produtividade e diminuindo o absenteísmo e rotatividade. A seguir, apresentam-se os procedimentos metodológicos da pesquisa. em trabalhos de pesquisa. Este estudo utilizou as duas leis, pois descreveu a quantidade de artigos publicados em jornais internacionais e avaliou as citações dos artigos publicados.

Por meio dessa técnica, analisaram-se as publicações internacionais, na língua inglesa, nas bases Periódicos Capes (2018) e Scopus (2018). Deve-se esclarecer que Scopus é uma plataforma de pesquisa online usada por milhares de instituições e milhões de usuários em todo o mundo, com bancos de dados de qualidade e recursos de pesquisa. Ela auxilia pesquisadores a encontrar, rapidamente, as informações, os artigos, as dissertações, entre outros. Já o Periódicos Capes é um repositório de publicações avaliadas pela Coordenação de Aperfeiçoamento de Pessoal de Nível Superior 
- Capes, fundação mantida pelo Ministério de Educação no Brasil.

Foi possível identificar informações sobre as pesquisas referentes ao engajamento, engajamento no trabalho e a escala de engajamento "Utrech", no sentido de caracterização e quantificação das publicações disponíveis sobre os temas.

Para a pesquisa em questão, inicialmente foi definido que os artigos de interesse seriam aqueles das publicações disponíveis nas bases já indicadas e que tratassem do engajamento no trabalho, a partir das palavras-chave: "Engagement", "Work Engagement" e "Ultrech Work Engagement Scale". A busca foi realizada nos próprios sites dos repositórios entre os meses de agosto e outubro de 2018.

\section{RESULTADOS E ANÁLISES}

A pesquisa da palavra "Engagement" no Periódicos Capes (2018), com todos os filtros, resultou em 44.565 artigos, foram analisados os primeiros 400 resultados mais relevantes e pré-selecionados 72 artigos, que foram aqueles que, no título, no resumo e nas palavras-chave tiveram alguma ligação com o tema de interesse. No site Scopus (2018), foram encontrados 4.517 resultados; foram analisados os 100 primeiros e pré-selecionados, a partir dos mesmos critérios, 10 artigos. Quanto à palavra de busca "Work Engagement", foram localizados 2.274 resultados, sendo analisados os 100 primeiros e pré-selecionados, a partir dos mesmos critérios, 31 artigos no Periódicos Capes. No Scopus, fo-

Figura 1 - Relação das Palavras-Chave utilizadas para pesquisa nos periódicos

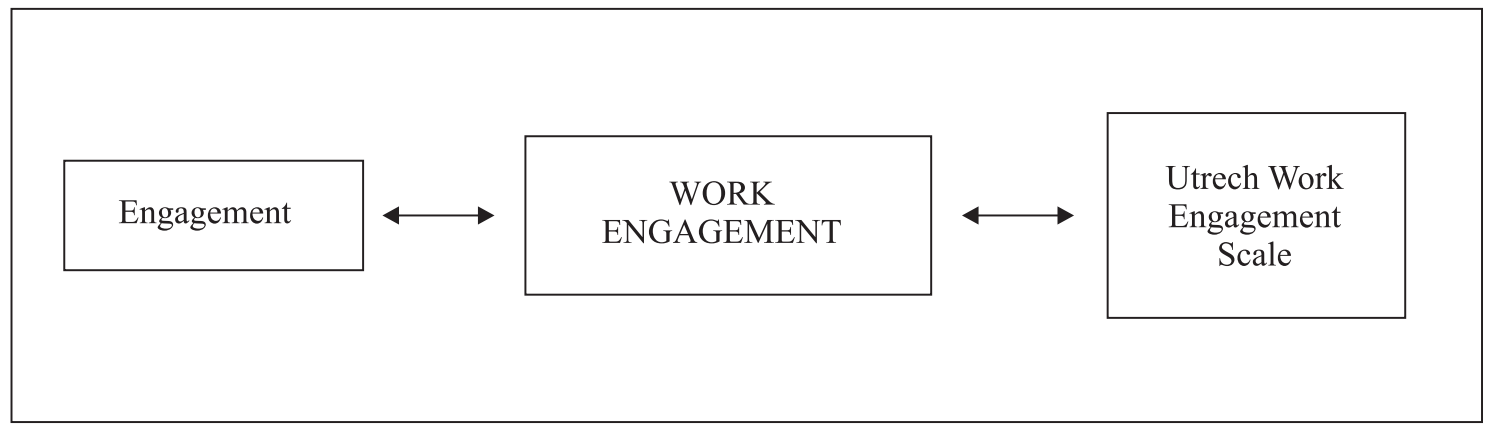

Fonte: dados da pesquisa.

Para realizar a pesquisa, foram utilizados filtros de direcionamento dos resultados por período, entre 2008 e 2018, apenas na língua inglesa, periódicos revisados por pares e publicados em revistas científicas. Então foram utilizados filtros, por área do conhecimento, que tivessem foco em negócios, engajamento no trabalho, na motivação e na liderança. E, por fim, utilizou-se a ordem "por relevância", para observar os artigos com maior número de citações.

Optou-se pelo período dos últimos 10 anos por ser um construto relativamente novo na área, por isso um período maior para encontrar os trabalhos. O Periódicos Capes foi escolhido por se tratar de uma base que contém um número bem expressivo de revistas de diferentes áreas; e o Scopus por ser uma base que contém, primordialmente, artigos internacionais. $\mathrm{O}$ uso das palavras-chave deu-se devido à busca pelo construto: "Engagement", que é tema da pesquisa; "Work Engagement" para especificar a área de interesse da pesquisa, em administração; e a palavra "Utrech Work Engagament Scale" por ser o principal método utilizado para medir escalas de engajamento no trabalho.

Quanto aos filtros, esta pesquisa é relacionada à área de administração e, mais especificamente, com foco no comportamento organizacional e gestão de pessoas, por isso foram utilizados filtros que estivessem ligados a essas áreas, de modo que a busca nas bases apenas mostrasse pesquisas que foram realizadas nessas áreas de interesse. A seguir apresentam-se os resultados e análises. 
ram encontrados 791 resultados, analisamos os 100 primeiros e não houve pré-seleções.

Quanto à palavra "Utrech Work Engagement Scale", foram identificados cinco artigos no periódico Capes, porém apenas um estava de acordo com os objetivos deste trabalho; na base Scopus não foram encontrados resultados para essa palavra.

Essas metodologias utilizadas justificam-se pelos resultados das pesquisas terem sido muito grandes, sendo impossível, com o tempo disponível para pesquisa, verificar todos os títulos dos resultados; por isso, optou-se por utilizar uma ordem de importância dos artigos, fornecida pela própria base, e analisar os primeiros 400 resultados nos Periódicos Capes e os primeiros 100 do Scopus. Além disso, o critério utilizado para a seleção dos artigos foi baseado na área em que o artigo foi desenvolvido, na administração, nos recursos humanos e na gestão de pessoas, com foco para os estudos realizados com os funcionários de empresas, ou estudos que falassem sobre engajamento aplicado ao trabalho com relação a outros construtos da área de recursos humanos, como satisfação, motivação, performance e outros.

Tabela 1 - Quantificação de artigos sobre o tema de engajamento no trabalho por base de dados e anos selecionados

\begin{tabular}{|c|c|c|c|c|}
\hline Ano & Base pesquisada & Total de artigos encontrados & Artigos analisados & Total por Ano \\
\hline 2010 & P. CAPES & 3 & 3 & \multirow{2}{*}{3} \\
\hline & SCOPUS & 0 & 0 & \multirow{2}{*}{6} \\
\hline 2011 & P. CAPES & 12 & 0 & \multirow{2}{*}{5} \\
\hline & SCOPUS & 2 & 4 & \multirow{2}{*}{5} \\
\hline 2012 & P. CAPES & 11 & 1 & \multirow{2}{*}{0} \\
\hline & SCOPUS & 16 & 4 & \multirow{2}{*}{1} \\
\hline 2013 & P. CAPES & 17 & 0 & \multirow{2}{*}{0} \\
\hline & SCOPUS & 4 & 0 & \multirow{2}{*}{0} \\
\hline 2014 & P. CAPES & 15 & 0 & \multirow{2}{*}{0} \\
\hline & SCOPUS & 0 & 0 & 2 \\
\hline & P. CAPES & 0 & 0 & 0 \\
\hline & SCOPUS & 0 & 0 & 0 \\
\hline
\end{tabular}

Fonte: dados da pesquisa.
O resultado preliminar da busca apresentou 112 artigos que tratavam da temática escolhida. Desse total, foram selecionados, a partir do número de citações no Google Acadêmico, os 20 artigos com maior incidência, pois foi o critério de linha de corte dos trabalhos publicados para análise, todos com mais de 150 citações.

Nas tabelas 2 e 3, estão dispostos os 20 artigos que foram efetivamente lidos e analisados, de modo a destacar suas principais conclusões e contribuições para o entendimento do conceito de engajamento no trabalho e suas implicações práticas. Primeiramente, apresenta-se a tabela 2, com os artigos selecionados do Periódicos Capes; e na tabela 3, os artigos selecionados da base Scopus. 
Tabela 2 - Artigos Científicos relevantes sobre a temática pesquisada, de acordo com número de citações no Google Acadêmico, na base Periódicos Capes, e principais conclusões e contribuições

\begin{tabular}{|c|c|c|}
\hline Título (AUTORES, ANO) & $\begin{array}{c}\mathbf{N}^{0} \text { de } \\
\text { Citações }\end{array}$ & Conclusões e Contribuições \\
\hline $\begin{array}{l}\text { Work Engagement: a qualitative } \\
\text { review and off its relations } \\
\text { with task add contextual } \\
\text { performance (CHRISTIAN; } \\
\text { SLAUGHTER, 2011). }\end{array}$ & 1509 & $\begin{array}{l}\text { Testaram o papel do engajamento como um mediador da } \\
\text { relação entre antecedentes e desempenho no trabalho. Em } \\
\text { suma, os resultados sugerem que o engajamento no trabalho } \\
\text { é uma construção útil que merece mais atenção. }\end{array}$ \\
\hline $\begin{array}{l}\text { Safety at Work: a meta-analytic } \\
\text { investigation of the link between job } \\
\text { demands, job resources, burnout, } \\
\text { engagement and safety outcomes } \\
\text { (NAHRGANG; MORGESON; } \\
\text { HOFMANN, 2010). }\end{array}$ & 892 & $\begin{array}{l}\text { O burnout estava negativamente relacionado ao trabalho } \\
\text { seguro, mas o engajamento motivou os funcionários e estava } \\
\text { positivamente relacionado ao trabalho seguro. Um ambiente } \\
\text { de apoio foi o recurso de trabalho mais consistente em } \\
\text { termos de explicação da variação nos resultados de burnout, } \\
\text { engajamento e segurança. }\end{array}$ \\
\hline $\begin{array}{l}\text { Weekly work engagement and } \\
\text { performance: A study among } \\
\text { starting teachers (BAKKER; } \\
\text { BAL, 2010). }\end{array}$ & 810 & $\begin{array}{l}\text { Os níveis semanais de autonomia, a troca com o supervisor } \\
\text { e as oportunidades de desenvolvimento foram positivamente } \\
\text { relacionados ao engajamento semanal, que, por sua } \\
\text { vez, foi relacionado, positivamente, ao desempenho do } \\
\text { trabalho semanal. Além disso, o envolvimento no trabalho } \\
\text { momentâneo foi positivamente relacionado aos recursos do } \\
\text { trabalho na semana seguinte. }\end{array}$ \\
\hline $\begin{array}{l}\text { An Evidence-Based Model of } \\
\text { Work Engagement (BAKKER, } \\
\text { 2011). }\end{array}$ & 768 & $\begin{array}{l}\text { Os recursos profissionais e pessoais são os principais } \\
\text { indicadores de engajamento. Esses recursos ganham sua } \\
\text { importância no contexto de altas demandas de trabalho. } \\
\text { Trabalhadores engajados estão mais abertos a novas } \\
\text { informações, mais produtivos e mais dispostos a irem } \\
\text { além. Os funcionários engajados proativamente mudam seu } \\
\text { ambiente de trabalho para permanecer engajados. }\end{array}$ \\
\hline $\begin{array}{l}\text { Do burnout and work engagement } \\
\text { predict depressive symptoms and } \\
\text { life satisfaction? A three-wave seven- } \\
\text { year prospective study (HAKANEN; } \\
\text { SCHAUFELI, 2012). }\end{array}$ & 507 & $\begin{array}{l}\text { O bem-estar relacionado ao trabalho prediz o bem-estar } \\
\text { geral em longo prazo. Burnout e engajamento no trabalho } \\
\text { não são opostos diretos. Em vez disso, ambos têm impactos } \\
\text { incrementais únicos na satisfação com a vida e nos sintomas } \\
\text { depressivos. }\end{array}$ \\
\hline $\begin{array}{l}\text { Do transformational leaders } \\
\text { enhance their followers' daily } \\
\text { work engagement? (TIMS; } \\
\text { BAKKER;XANTHOPOULOU, } \\
\text { 2011). }\end{array}$ & 481 & $\begin{array}{l}\text { A liderança transformacional se relacionava positivamente } \\
\text { ao engajamento dos funcionários, e os níveis de otimismo } \\
\text { mediam esse relacionamento. No entanto, a autoeficácia não } \\
\text { atuou como mediador. }\end{array}$ \\
\hline $\begin{array}{l}\text { Proactive personality and job } \\
\text { performance: The role of job } \\
\text { crafting and work engagement } \\
\text { (BAKKER; TIMS; DERKS, } \\
\text { 2012). }\end{array}$ & 415 & $\begin{array}{l}\text { Os funcionários que se caracterizavam por uma personalidade } \\
\text { proativa tinham maior probabilidade de criar seus empregos; a } \\
\text { criação de empregos, por sua vez, era preditiva de engajamento } \\
\text { no trabalho (vigor, dedicação e absorção) e classificações de } \\
\text { colegas no desempenho da função. Na medida em que os } \\
\text { funcionários ajustam proativamente seu ambiente de trabalho, } \\
\text { eles conseguem se manter engajados e ter um bom desempenho. }\end{array}$ \\
\hline $\begin{array}{l}\text { Crafting a job on a daily basis: } \\
\text { Contextual correlates and } \\
\text { the link to work engagement } \\
\text { (PETROU et al., 2012). }\end{array}$ & 381 & $\begin{array}{l}\text { Os resultados sugerem que a elaboração de trabalhos é um } \\
\text { comportamento diário dos funcionários, com implicações } \\
\text { para a prática de gestão. }\end{array}$ \\
\hline
\end{tabular}




\begin{tabular}{|c|c|c|}
\hline $\begin{array}{l}\text { Daily transactional and } \\
\text { transformational leadership and } \\
\text { daily employee engagement } \\
\text { (BREEVAART et al., 2013). }\end{array}$ & 289 & $\begin{array}{l}\text { A liderança transformacional e a recompensa contingente } \\
\text { contribuíram para um ambiente de trabalho mais favorável } \\
\text { (mais autonomia e apoio), enquanto gerenciamento por } \\
\text { exceção ativo resultou em um ambiente de trabalho menos } \\
\text { favorável (menos autonomia) para os cadetes. Importância } \\
\text { da liderança diária para o engajamento diário dos seguidores. }\end{array}$ \\
\hline $\begin{array}{l}\text { Job burnout and employee } \\
\text { engagement: a meta-analytic } \\
\text { examination of construction } \\
\text { proliferation (COLE et al., 2012). }\end{array}$ & 271 & $\begin{array}{l}\text { As correlações de nível de dimensão entre burnout e engajamento são } \\
\text { altas; as dimensões de burnout e engajamento apresentam um padrão } \\
\text { semelhante de associação com correlatos e o controle de burnout } \\
\text { em equações de meta-regressão reduziu substancialmente os efeitos } \\
\text { associados ao engajamento. Esses achados sugerem que dúvidas } \\
\text { sobre a distinção funcional das dimensões subjacentes ao burnout e } \\
\text { ao engajamento não podem ser descartadas como pura especulação. }\end{array}$ \\
\hline $\begin{array}{l}\text { A Tale of Passion: linking } \\
\text { job passion and cognitive } \\
\text { engagement to employee work } \\
\text { performance (HO; WONG; } \\
\text { LEE, 2011). }\end{array}$ & 212 & $\begin{array}{l}\text { Empregados com paixão harmoniosa tiveram melhor } \\
\text { desempenho no trabalho, e essa relação foi mediada, } \\
\text { principalmente, pela absorção cognitiva, ou seja, a intensidade } \\
\text { do foco e da imersão vivenciada pelos funcionários ao } \\
\text { trabalhar. No entanto, mesmo que a paixão obsessiva estivesse } \\
\text { relacionada negativamente à atenção cognitiva, ela não tinha } \\
\text { uma relação significativa com o desempenho geral do trabalho. }\end{array}$ \\
\hline $\begin{array}{l}\text { Modeling corporate citizenship, } \\
\text { organizational trust, and } \\
\text { work engagement based on } \\
\text { attachment theory (LIN, 2010). }\end{array}$ & 202 & $\begin{array}{l}\text { A cidadania corporativa e o sucesso organizacional dificilmente } \\
\text { podem ser separados. As empresas que aprimoram sua cidadania } \\
\text { corporativa, provavelmente, aumentarão imensamente a confiança } \\
\text { organizacional e o engajamento no trabalho de seus funcionários. }\end{array}$ \\
\hline $\begin{array}{l}\text { The Affective Shift Model of } \\
\text { Work Engagement (SCHMITT; } \\
\text { KUHNEL; FRESE, 2011). }\end{array}$ & 191 & $\begin{array}{l}\text { Em apoio ao modelo de mudança afetiva, o humor negativo } \\
\text { e os eventos negativos vivenciados na manhã de um dia de } \\
\text { trabalho foram, positivamente, relacionados ao trabalho no } \\
\text { período da tarde, se o humor positivo no intervalo de tempo } \\
\text { entre a manhã e a tarde fosse alto. Diferenças individuais na } \\
\text { afetividade positiva moderam as relações internas. }\end{array}$ \\
\hline
\end{tabular}

The Effect of Authentic Leadership on Employee Trust and Employee Engagement (WANG; HSIEH, 2013).
Os resultados mostraram que a consistência dos supervisores entre palavras e ações, bem como suas percepções morais, estão positivamente relacionadas ao engajamento dos funcionários, enquanto apenas a consistência dos supervisores entre palavras e ações está positivamente relacionada à confiança dos funcionários. Além disso, a confiança dos funcionários mostrou-se positivamente relacionada ao engajamento dos funcionários. Finalmente, descobriuse que a confiança dos funcionários tinha um efeito mediador parcial entre a liderança autêntica e o engajamento dos funcionários.

O nível de recuperação matutino previu o engajamento no trabalho, e esse previu o nível de recuperação subsequente no final do dia de trabalho após o controle do nível de recuperação matinal. Os resultados sugerem que a recuperação se traduz em engajamento no trabalho dos funcionários e o engajamento no trabalho, por sua vez, impede a falta de recuperação ao longo do dia, principalmente, quando as restrições situacionais são baixas.

Os resultados mostram que o funcionamento autêntico media 161 a relação entre atenção plena e engajamento no trabalho, parcialmente para o relacionamento estático e totalmente para o relacionamento dinâmico. 
Sobre os artigos dos Periódicos Capes, é interessante observar que alguns autores se repetem, os artigos com mais citações, com destaque para Bakker, A. R. da Universidade Erasmus de Rotterdam, na Holanda, que é autor de três desses artigos; um deles com 810 citações, publicado em 2010 tem coautoria em outros três desses trabalhos.

As principais contribuições desses trabalhos, apresentados na tabela 3, são quanto aos avanços da teoria, de modo a fazer revisões de literatura, ou de modo a entender as relações com outros construtos, com uso de questionários e métodos estatísticos, de abordagem quantitativa. Alguns desses construtos são liderança, autonomia, segurança, motivação, satisfação, rede de apoio, recursos pessoais e profissionais, como performance, proatividade, "job crafting", paixão pelo trabalho também quanto a humores, positividade, burnout, depressão.

Esses artigos abordam diversos aspectos antecedentes e subsequentes do engajamento do trabalho, ou visam contribuir para a teoria e a construção do conceito, ou ainda para compreender as relações que ele estabelece com outros construtos organizacionais e características pessoais, tanto dos líderes, quanto dos funcionários.

Tabela 3 - Artigos Científicos relevantes sobre a temática pesquisada, de acordo com número de citações no Google Acadêmico, na base Scopus, e principais conclusões e contribuições

\begin{tabular}{l|c|l}
\hline \multicolumn{1}{c|}{ Título (Base/ ano) } & $\begin{array}{c}\mathbf{N}^{\mathbf{0}} \text { de } \\
\text { Citações }\end{array}$ & \multicolumn{1}{|c}{ Conclusões e Contribuições } \\
\hline $\begin{array}{l}\text { Work engagement and } \\
\text { machiavellianism in } \\
\text { the ethical leadership } \\
\text { process (HARTOG; } \\
\text { BELSCHACK, 2012). }\end{array}$ & 251 & $\begin{array}{l}\text { Os efeitos positivos do comportamento ético do líder, } \\
\text { provavelmente, serão suprimidos quando os líderes forem } \\
\text { altamente maquiavélicos. Os efeitos do comportamento ético do } \\
\text { líder no engajamento são menos fortes quando os líderes éticos } \\
\text { são altos em oposição ao baixo nível de maquiavelismo. }\end{array}$ \\
\hline $\begin{array}{l}\text { Collective Organizational } \\
\text { Engagement: linking } \\
\text { motivational antecedents, } \\
\text { strategic implementation } \\
\text { and firm level performance } \\
\text { (BARRICK et al., 2015). }\end{array}$ & 194 & $\begin{array}{l}\text { Agrupando os recursos de melhoria de motivação da empresa } \\
\text { e perseguindo seus objetivos, os membros da organização } \\
\text { têm maior probabilidade de desenvolver um nível coletivo de } \\
\text { engajamento que, por sua vez, resulta em maior desempenho } \\
\text { financeiro da empresa. }\end{array}$ \\
\hline $\begin{array}{l}\text { Workplace Engagement } \\
\text { and generational } \\
\text { differences in values } \\
\text { (SCHULLERY, 2013). }\end{array}$ & 191 & $\begin{array}{l}\text { Pesquisas realizadas com 16.000 alunos do ensino médio de três } \\
\text { gerações sobre valores intrínsecos, extrínsecos, sociais, de lazer } \\
\text { e altruístas no trabalho mostram que apenas o valor altruísta não } \\
\text { é estatisticamente diferente. Quando agregadas, essas diferenças } \\
\text { geracionais têm impacto prático perceptível. Na sala de aula, o } \\
\text { engajamento é essencial para a aprendizagem. }\end{array}$ \\
\hline $\begin{array}{l}\text { Employee engagement, } \\
\text { organizational } \\
\text { performance and } \\
\text { individual well-being: } \\
\text { exploring the evidence, } \\
\text { developing the theory } \\
\text { (TRUSS et al., 2013). }\end{array}$ & $\begin{array}{l}\text { Existe uma clara necessidade de mais pesquisas que avancem } \\
\text { nossa compreenão dos processos psicológicos subjacentes ao } \\
\text { engajamento, o significado preciso e o status da construção de } \\
\text { engajamento, as experiências vividas de "fazer" engajamento } \\
\text { e "estar" engajado, questões de poder e engajamento e os } \\
\text { processos de nível micro e macro em torno da promulgação do } \\
\text { engajamento dentro das configurações organizacionais. }\end{array}$ \\
\hline
\end{tabular}

Fonte: dados da pesquisa.

Nos artigos da base Scopus, não aparecem repetições dos autores; porém, destacando os principais autores dos artigos, têm-se os seguintes: Deanne N. Den Hartog, da Amsterdam Bussiness School da Universidade de Amsterdam, com o artigo de 251 citações; Murray R.
Barrick, do Mays Bussiness School da Universidade do Texas, com o artigo de 194 citações; Nancy M. Schullery do Department of Business Information Systems da Western Michigan University, com o artigo de 191 citações; e, por fim, Catherine Truss da Kent Business School 
da University of Kent, in the United Kingdom. Quanto às principais contribuições desses artigos, tem-se achados quanto aos construtos de liderança, motivação individual e coletiva, os valores das gerações e seus impactos para as diferenças quanto ao nível de engajamento no trabalho e quantos aos processos psicológicos envolvidos no engajamento do trabalho.

Na figura 2, a seguir, há um levantamento dos principais subtemas em gestão de pessoas que são relacionados com o tema de engajamento no trabalho, dos 20 artigos selecionados.
Figura 3 - Quantidade de estudos por país de origem dos autores

\section{Number of Studies}

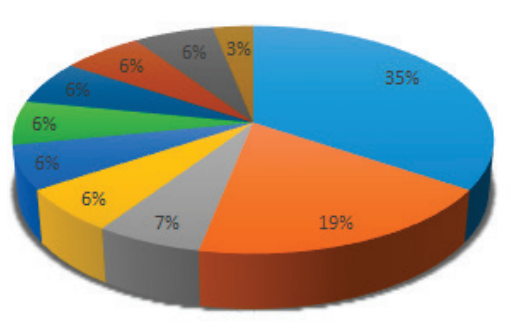

- Netherlands

- USA

- Germany

- Begium

- Canada

a Finland

- Norway

- Singapore

- Taiwan

- United King dor

Fonte: dados da pesquisa.

Figura 2 - Principais temas relacionados com engajamento no trabalho nos artigos analisados

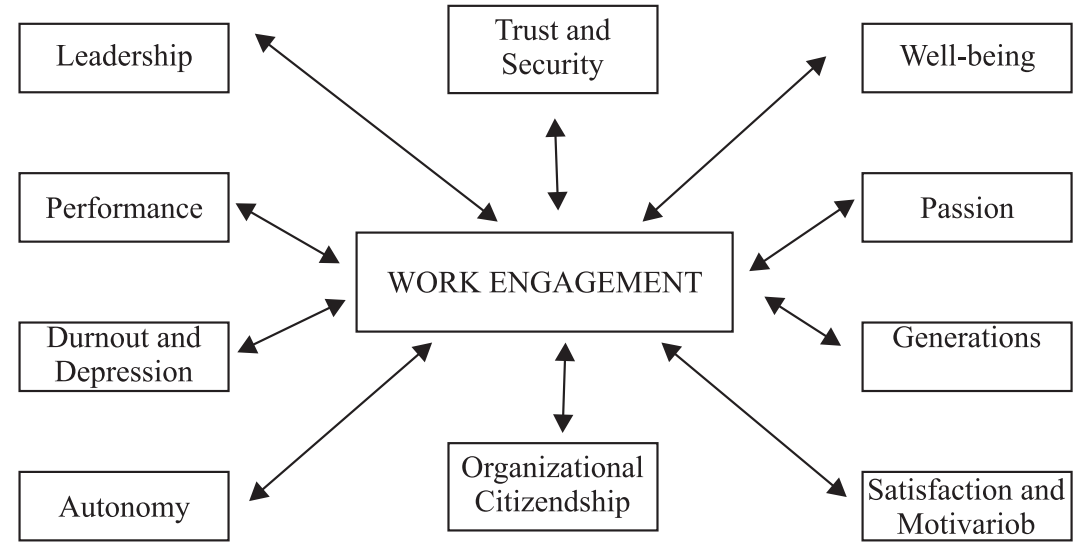

Fonte: dados da pesquisa.

A partir da figura 1, observa-se que as pesquisas internacionais de engajamento no trabalho visam compreender quais são os fatores organizacionais que influenciam e são influenciados pelo tema. Com maior incidência em liderança, que mais aparece entre os artigos, como os diferentes estilos podem aumentar ou diminuir o engajamento; assim como relações com o "burnout" e a depressão e outras situações do ambiente de trabalho, como autonomia, segurança, cidadania e confiança, mas também fatores intrínsecos, como satisfação e motivação no trabalho, paixão pelo trabalho e a própria performance.

Como um dos critérios da nossa pesquisa foi identificar artigos que fossem internacionais, na língua inglesa, também se faz uma análise dos países de origem dos autores desses 20 artigos selecionados, cujos dados estão apresentados na figura 3, a seguir:
Ao observar a figura 3, o que fica explícito é que a produção internacional sobre engajamento no trabalho tem grande concentração de autores holandeses, país onde foi desenvolvido a Escala de Engajamento do Trabalho Utrech. Também é importante salientar que grande parte dos artigos foram resultados de parcerias entre autores e coautores de diferentes países. Como um dos critérios da pesquisa era que fossem artigos internacionais, não se verificou a presença de artigos de autores brasileiros.

Julgou-se importante apresentar quais são os tipos de abordagens metodológicas, utilizadas pelos pesquisadores nos artigos selecionados. Para tal, elaborou-se a figura 4, com as características de cada estudo, o qual aponta os tipos de abordagens e a quantidade de estudos encontrados. 
Figura 4 - Número de estudos abordagem metodológica

Number of Studies

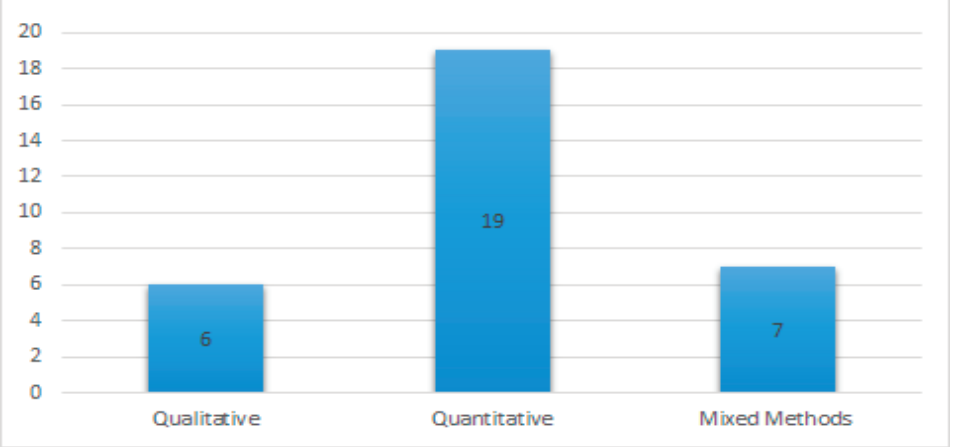

Fonte: dados da pesquisa.

Quanto às metodologias utilizadas, há uma predominância do uso de abordagens quantitativas, pelo uso de escalas para medição de engajamento como a Utrech, e outras escalas para medir construtos ligados ao tema principal, como, "burnout", atenção plena, satisfação, motivação, entre outros. Nas abordagens qualitativas, o que se destaca são revisões de literatura e o uso de diários, em que os respondentes relatam suas experiências.

Por fim, julgou-se importante observar as revistas de publicação dos artigos, sendo elas divididas entre revistas da área de administração e psicologia, principalmente, devido à natureza do construto que está ligada à área de gestão de pessoas.

Tabela 4 - Revistas internacionais que publicaram os artigos analisados sobre engajamento no trabalho período de 2007 a 2018

\begin{tabular}{l|c|c}
\hline \multicolumn{1}{c|}{ Revistas } & $\begin{array}{c}\text { Número de } \\
\text { Estudos }\end{array}$ & Fator de Impacto \\
\hline Journal of Applied Psychology & 3 & $4.130(2016)$ \\
\hline Journal of Bussiness Ethics & 2 & $2.917(2017)$ \\
\hline Journal of Occupational and Organizational Psychology & 2 & $2.419(2012)$ \\
\hline Journal of Management & 1 & 8.080 \\
\hline Academy of Management Journal & 1 & $7.417(2016)$ \\
\hline Journal of Management Studies & 1 & 5.329 \\
\hline Current Directions in Psychological Science & 1 & $4.673(2017)$ \\
\hline Personnel Psychology & 1 & $4.362(2016)$ \\
\hline Journal of Organizational Behavior & 1 & 4.229 \\
\hline Journal of Affective Disorders & 1 & $3.570(2015)$ \\
\hline The Leadership Quarterly & 1 & $3.307(2017)$ \\
\hline Human Relations & 1 & 3.043 \\
\hline Journal of Vocational Behavior & 1 & $2.555(2016)$ \\
\hline The Internacional Journal of Human Resourse Management & 1 & $2.425(2017)$ \\
\hline Business Communication Quarterly & 1 & $0.84(2015)$ \\
\hline Social Behavior and Personality & 1 & $0.548(2016)$ \\
\hline Fonte: & &
\end{tabular}

Fonte: dados da pesquisa. 
Quanto às revistas de publicação dos artigos, tem-se como destaque a "Journal of Applied Psychology", da Associação Americana de Psicologia, com três dos artigos publicados e fator de impacto 4.130, em 2016. Em seguida, com dois dos artigos, a "Journal of Bussiness Ethics", de fator de impacto de 2,917, em 2017; e a "Journal of Occupational and Organizational Psychology" da Sociedade Inglesa de Psicologia, com dois dos artigos e fator de impacto 2.419, em 2012.

Quanto às outras revistas, existem apenas um dos artigos analisados, porém há destaque para a "Journal of Management" e a "Academy of Management Journal", com 8.080 e 7.417 de fator de impacto, respectivamente. Assim, também se observa que as principais áreas de publicação dos artigos sobre engajamento do trabalho são na Administração, Gestão e na Psicologia. A seguir, apresentam-se as considerações finais do estudo, com suas contribuições, limitações e apontamentos para estudos futuros.

\section{CONSIDERAÇÕES FINAIS}

Este artigo objetivou desenvolver uma análise bibliométrica da produção de artigos internacionais sobre o construto Engajamento no Trabalho, nas bases Periódicos Capes e Scopus de modo a compreender melhor esse conceito e o que tem sido estudado sobre ele nos últimos 10 anos (2008-2018). Discorreu-se, inicialmente, sobre o tema engajamento no trabalho como contemporâneo em gestão de pessoas, apresentando seus principais conceitos e sua importância de estudo no contexto atual.

Quanto às questões de pesquisa, foi possível identificar que existem diversos artigos internacionais que falam sobre engajamento do trabalho, mais de 45.000 artigos nos periódicos Capes e mais de 40.000 artigos no Scopus; porém foram identificados 112 artigos da área dentro dos parâmetros definidos para essa pesquisa. Quanto à origem dos autores, observou-se que há uma predominância de autores holandeses (35\%), americanos (19\%), seguido de outros países europeus e destaque para Taiwan e Singapura, com 6\% cada um.

As principais contribuições dos artigos são quanto ao desenvolvimento do conceito do construto "Engajamento no Trabalho", entendido como um estado mental de vigor, dedicação e absorção ligados à tarefa realizada e à natureza do trabalho; também há contribuições sobre a relação desse construto com outros da área de comportamento organizacional e recursos humanos, como positivamente relacionado com a paixão que os funcionários têm com seu trabalho, que diminui a incidência de sintomas depressivos, e alguns estudos que tentam compreender a relação dicotômica com o "burnout"; alguns afirmam que são construtos contrários, e outros que dizem que pode haver alguma relação direta.

Os subtemas observados são diversos, tanto quanto à natureza do sentimento de engajamento, como atenção plena, autenticidade, características pessoais, como proatividade e performance, assim como relações com a natureza do trabalho, como, a autonomia, o estilo de liderança do chefe, confiança e segurança do trabalho e cidadania organizacional.

Quanto ao perfil metodológico adotado pelos estudos, observou-se uma preferência em abordagens quantitativas, como questionários com Escala Likert, "surveys", a "Utrech Work Engagement Scale". Também se percebe uma utilização significativa de um mix de metodologias, principalmente quando o artigo se propõe a compreender diferentes construtos que se relacionam com o tema principal, utilizando-se revisões de literatura para compreender os conceitos e também escalas para medi-las em amostras. E por fim, a utilização da abordagem qualitativa, com menor incidência, com o uso de revisão da literatura e um artigo que utilizou relatos de experiência por meio de diários semanais.

Quanto às principais revistas de publicações desses estudos, identificou-se que não há uma principal que se destaca, pois os artigos estão espalhados entre diferentes "journals", mas com predominância para duas áreas da ciência, que é a psicologia e a administração. Isso se deve pela natureza do construto, que, inicialmente, é um conceito da psicologia que migrou para a admi- 
nistração quando começou a ser interesse também da área de gestão de pessoas e recursos humanos, como um construto ligado ao trabalho.

Este estudo contribui para compreender as recentes publicações sobre engajamento no trabalho e seus conceitos em periódicos internacionais, bem como os principais temas de estudo e autores e seus países de origem. Além disso, foi possível fazer um levantamento bibliométrico sobre esses estudos e observar quais as características predominantes desses, como a origem dos autores, metodologias utilizadas, principais contribuições, as revistas que mais publicam sobre o assunto e as principais áreas que se interessam pelo tema.

Além das contribuições, este estudo possui, como limitação, as duas bases de dados escolhidas: periódicos Capes e Scopus, existindo diversas outras. Neste sentido, é interessante que os estudos futuros relacionados ao engajamento no trabalho, além de trabalhar as temáticas ainda incipientes, procurem diagnosticar ou mapear os interesses pelo tema/subtemas em relação a outros países de origem dos autores ou, ainda, investigar estudos ainda mais recentes, em busca dos novos subtemas, mais aprofundados que possam estar relacionados com o construto em questão.

\section{REFERÊNCIAS}

ARAÚJO, C. A. Bibliometria: evolução histórica e questões atuais. Revista em Questão, Porto Alegre, v. 12, n. 1, p. 11-32, 2006.

AVEIRO, R. O. et al. Funcionário Público Engajado no Trabalho? uma análise do engajamento de profissionais da tecnologia da informação do Serviço Público Federal. In: ENCONTRO NACIONAL DE ENGENHARIA DE PRODUÇÃO, 38., 2017, Maceió. Anais [...]. Maceió: Enanpad, 2017.

BAKKER, A. B. An Evidence-Based Model of Work Engagement. Current Directions in Psychological Science, v. 20, n. 4, p. 265-269, 2011.
BAKKER, A. B.; BALL, P. M. Weekly work engagement and performance: A study among starting teachers. Journal of Occupational and Organizational Psychology, n. 83, p. 189-206, 2010.

BAKKER, A. B.; TIMS, M.; DERKS, D. Proactive personality and job performance: the role of job crafting and work engagement. Human Relations, v. 65, n. 10, p. 1359-1378, 2012.

BARRICK, M. R. et al. Collective organizational engagement: linking motivational antecedents, strategic implementation, and firm performance. Academy of Management Journal, v. 58, n. 1, p. 111-135, 2015.

BREEVAART, K. et al. Daily transactional and transformational leadership and daily employee engagement. Journal of Occupational and Organizational Psychology, v. 87, n. 1, p. 138-157, 2013.

CHRISTIAN, M. C.; SLAUGHTER, J. Work engagement: a meta-analytic review and directions for research in an emerging area. Personnel Psychology, v. 64, p. 89-136, 2011.

COLE, M. C. et al. Job Burnout and Employee Engagement: A Meta-Analytic Examination of Construct Proliferation. Journal of Management, v. 38, n. 5, p. 1550-1581, 2012.

HANAKEN, J. J.; SCHEUFELI, W. B. Do burnout and work engagement predict depressive symptoms and life satisfaction? A threewave seven-year prospective study. Journal of Affective Disorders, v. 141, p. 415-424, 2012.

HARTOG, D. N. D.; BELSCHACK, F. D. Work Engagement and Machiavellianism in the Ethical Leadership Process. Journal of Business Ethics, v. 107, p. 35-47, 2012.

HO, V.; WONG, S-S.; LEE, S. H. A Tale of Passion: Linking Job Passion and Cognitive Engagement to Employee Work Performance. 
Management Faculty Publications, v. 48, 2011.

KAHN, W. A. Psychological Conditions of Personal Engagement and Disengagement at Work. Academy of Management Journal, v. 33, n. 4, 1990.

LEROY, H. et al. Mindfulness, authentic functioning, and work engagement: a growth modeling approach. Journal of Vocational Behavior, v. 82, p. 238-247, 2013.

LIN, C. P. Modeling Corporate Citizenship, Organizational Trust, and Work Engagement Based on Attachment Theory. Journal of Business Ethics, v. 94, p. 517-531, 2010.

NAHRGANG, J. D.; MORGESON, F. P.; HORMANN, D. A. Safety at Work: A Meta-Analytic Investigation of the Link Between Job Demands, Job Resources, Burnout, Engagement, and Safety Outcomes. Journal of Applied Psychology, v. 96, n. 1, p. 71-94, 2010.

OLIVEIRA, L. B.; ROCHA, J. C. Engajamento no Trabalho: antecedentes individuais e situacionais e sua relação com a intenção de rotatividade. Revista Brasileira de Gestão de Negócios, v. 19, n. 65, p. 415-431, 2017.

PAULI, J. et al. Satisfação, conflitos e engajamento no trabalho para professores do ensino médio. Revista Pensamento Contemporâneo em Administração, v. 11, n. 4, 2017.

PERIÓDICOS CAPES. Ministério da Educação. Home. Disponível em: http://www.periodicos.capes.gov.br. Acesso em: 25 out. 2018.

PETROU, P. et al. Crafting a job on a daily basis: Contextual correlates and the link to work engagement. Journal of Organizational Behavior, v. 33, p. 1120-1141, 2012.

PORTO-MARTINS, P. C.; BASSO-MACHADO, P. G.; BENEVIDES-PEREIRA, A. M. T.
Engajamento no trabalho: uma discussão teórica. Rev. Psicol., v. 25, n. 3, p. 629-644, 2013.

SCHAUFELI, W. B. et al. The Measurement of Engagement and Burnout: a two sample confirmatory factor analytic approach. Journal of Happiness Studies, v .3, p. 71-92, 2002.

SCHMITT, A.; KUHNEL, J.; FRESE, M. The Affective Shift Model of Work Engagement. Journal of Applied Psychology, v. 96, n. 6, p. 1246-1257, 2011.

SCHULLERY, N. M. Workplace engagement and generational differences in values. Business Communication Quarterly, v. 76, n. 2, p. 252-265, 2013.

SCOPUS. Home. Disponível em: https://www. scopus.com/home.uri. Acesso em: 25 out. 2018.

SILVA, M. R.; HAYASHI, C. R. M.; HAYASHI, M. C. P. I. Análise bibliométrica e cintométrica: desafios para especialistas que atuam no campo. InCID: R. Ci. Inf. e Doc., v. 2, n. 1, p. 110129, 2011.

SONNENTAG, S. Recovery, work engagement, and proactive behavior: a new look at the interface between nonwork and work. Journal of Applied Psychology, v. 88, n. 3, p. 518-528, jun. 2003.

SONNENTAG, S. et al. Reciprocal Relations Between Recovery and Work Engagement: The Moderating Role of Job Stressors. Journal of Applied Psychology, v. 97, n. 4, p. 842-853, 2012.

TIMS, M.; BAKKER, A. B.; XANTHOPULOU, D. Do transformational leaders enhance their followers' daily work engagement? The Leadership Quarterly, v. 22, p. 121-131, 2011.

TRUSS, C. et al. Employee engagement, organizational performance and individual well-be- 
ing: exploring the evidence, developing the theory. The International Journal of Human Resource Management, v. 24, n. 14, 2013.

WANG, D. S.; HSIEH, C. C. The effect of authentic leadership on employee trust and employee engagement. Social Behavior and Personality, v. 41, n. 4, p. 613-624, 2013. 